\title{
Memahami Pekerjaan Roh Kudus dalam Pelayanan Gereja Berdasarkan 1 dan 2 Timotius
}

\author{
Gidion \\ Sekolah Tinggi Teologi Kristus Alfa Omega \\ gideonjosila@gmail.com
}

\begin{abstract}
The importance of the work of the Holy Spirit in the Church's history over time becomes a basic need for researching understanding of the role of the Holy Spirit in the church service. So the goal of this research is to analyze the letter of 1 and 2 Timothy regarding the doctrine of the Holy Spirit's role in church services. Specifically, the study using the exegesis principles to approach texts, while among historical analysis, context analysis, syntax analysis, analysis morphology, and lexical analysis of the text. So the results of this study explained that the role of the Spirit is the Holy provide an affirmation that Jesus is Lord, lead servants of God in the time of trouble, equipping servant of the Lord with the gift of ministry (2 Tim. 1: 6), stating prophecy (1 Tim. 4: 1), giving the power airport (1 Tim. 4:14), guiding people believe, teach, reveals the mind of God, inspired preaching of the word of God.
\end{abstract}

Keywords: church; church ministry; Holy Spirit; Timothy

\begin{abstract}
Abstrak: Pentingnya memahami pekerjaan Roh Kudus dalam sejarah gereja dari waktu ke waktu menjadi kebutuhan dasar untuk meneliti pemahaman tentang peran Roh Kudus dalam pelayanan gereja. Jadi tujuan dari penelitian ini adalah untuk menganalisis surat 1 dan 2 Timotius mengenai doktrin peran Roh Kudus dalam pelayanan gereja. Secara khusus, penelitian ini menggunakan prinsip-prinsip penafsiran untuk mendekati teks, sedangkan di antara analisis historis, analisis konteks, analisis sintaksis, analisis morfologi, dan analisis leksikal teks. Jadi hasil dari penelitian ini menjelaskan bahwa peran Roh adalah yang Kudus memberikan penegasan bahwa Yesus adalah Tuhan, memimpin hamba-hamba Allah di masa kesusahan, memperlengkapi hamba Tuhan dengan karunia pelayanan (2 Tim. 1: 6), yang menyatakan nubuat (1 Tim. 4: 1), memberikan kekuatan bandara (1 Tim. 4:14), membimbing orang-orang percaya, mengajar, mengungkapkan pikiran Allah, mengilhami pemberitaan firman Allah.
\end{abstract}

Kata kunci: gereja; pelayanan gereja; Roh Kudus; Timotius

\begin{tabular}{lll} 
Article Genesis : & Received: 14 November $2019 \quad$ Revised: - \\
\hline
\end{tabular}

Accepted: 31 December 2019

\section{PENDAHULUAN}

Pemahaman Pemimpin gereja tentang peranan Roh Kudus dalam pelayanan gereja juga sangat mempengaruhi keberhasilan Pemimpin gereja dalam memimpin pertumbuhan gereja lokal. Kelesuan rohani pada gereja masa kini adalah karena menolak pemahaman tentang karya Roh Kudus dalam gereja. Padahal secara prinsip, Roh Kuduslah yang berperan menghidupkan dan menggerakkan pertumbuhan gereja, serta mempersatukan orang-orang percaya pada Kristus. Roh Kudus sebagai inisiator pertumbuhan gereja, menjadi penentu perkembangan gereja dari masa ke masa. 
Dalam kitab Perjanjian Baru, Paulus suatu kali menuliskan surat kepada Timotius seorang Pemimpin gereja jemaat yang sedang menghadapi kompleksnya masalah pemimpin gereja. Surat-surat yang dimaksud adalah surat 1 dan 2 Timotius, surat-surat ini dikenal sebagai surat-surat pemimpin gereja sejak pada masa awal munculnya surat ini. Surat ini berisikan nasihat-nasihat Paulus tentang bagaimana menyelesaikan masalah-masalah pemimpin gereja, yang ditujukan kepada pemimpin gereja Timotius yang memimpin jemaat di Efesus. Pentingnya peranan Roh Kudus dalam sejarah Gereja dari masa kemasa menjadi dasar perlunya meneliti pemahaman tentang peranan Roh Kudus dalam pelayanan gereja. Memang ada beragam penafsiran dan cara pandang mengenai topik karya Roh Kudus. Hal ini menjadi dilema, sebab tidak sedikit Gereja yang secara aktif "berusaha" mengkerdilkan dan ada juga yang melebih-lebihkan makna dari peranan Roh Kudus. Pemahaman pemimpin gereja yang rendah tentang peranan Roh Kudus dalam pelayanan gereja dapat membatasi karya Roh Kudus di dalam pelayanan pemimpin gereja tersebut, dan itu berarti menambahkan masalah atau penghambat pertumbuhan gereja.

Anas Sudijono seorang pakar pendidikan menjelaskan, bahwa memahami merupakan kemampuan seseorang untuk mengerti sesuatu setelah mengetahui sesuatu. Dimana melalui pemahaman tersebut seorang dapat meginterpretasikan, dan mendemonstrasikannya dalam bentuk implementasi. ${ }^{1}$ Anwar Hadi seorang pakar pengembangan riset laboratorium mengatakan bahwa kesuksesan pelaksanaan audit internal laboraturiom, sangat ditentukan oleh

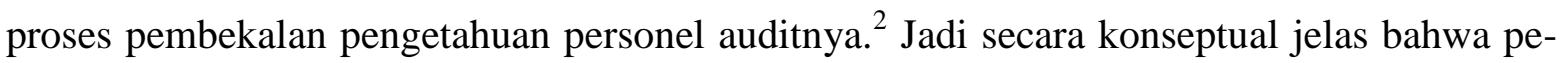
mahaman seseorang sangat berpengaruh terhadap implementasi atau penghayatan dari pemahaman. Demikian halnya dengan pemahaman seorang Pemimpin Gereja tentang peranan Roh Kudus dalam pelayanan Gereja, yang berpengaruh terhadap pelayanan pemimpin gereja. Jadi tujuan riset ini adalah melakukan analisa terhadap surat 1 dan 2 Timotius mengenai ajaran tentang peranan Roh Kudus dalam pelayanan gereja

\section{METODE}

Oleh karena tujuan penelitian bersifat riset pustaka dengan kajian ilmu hermeneutika, maka pendekatan yang digunakan untuk riset penelitian ini adalah metode kualitatif. Pendekatan kualitatif menekankan kepada kualitas data atau informasi penelitian. Gidion mengatakan bahwa penelitian kualitatif menekankan pada quality atau menemukan makna dibalik gejala sosial yang dapat dijadikan pelajaran berharga bagi pengembangan konsep teori. ${ }^{3}$ Secara khusus penelitian menggunakan prinsip-prinsip eksegesa untuk mendekati teks, adapun di antaranya dilakukan analisa historika, analisa konteks, analisa syntax, analisa morfology, dan juga analisa leksikal pada teks. Chrisna Wijaya dalam tulisannya menjelaskan bahwa

\footnotetext{
${ }^{1}$ Anas Sudijono, Pengantar Evaluasi Pendidikan (Jakarta: PT. Raja Grafindo Persada, 1996), 50.

${ }^{2}$ Anwar Hadi, Pemahaman Dan Penerapan ISO/IEC 17025 Persyaratan Umum Kompetensi Laboraturium Pengujian Dan Laboraturium Kalibrasi (Jakarta: Gramedia, 2007).

${ }^{3}$ Gidion, Metode Penelitian Teologi (Semarang: KAO Press, 2015), 53.

https://isbn.perpusnas.go.id/Account/SearchBuku?searchCat=Judul\&searchTxt=METODE+PENELITIAN+TE OLOGI.
} 
studi literature dilakukan dengan melakukan tinjauan pustaka yaitu buku-buku dan jurnal ilmiah yang terkait dengan topic penelitian. ${ }^{4}$

\section{PEMBAHASAN}

\section{Roh Kudus Meneguhkan Bahwa Yesus Adalah Tuhan}

1Timotius 3:16 berkata: "Dan sesungguhnya agunglah rahasia ibadah kita: "Dia, yang telah menyatakan diri-Nya dalam rupa manusia, dibenarkan dalam Roh; yang menampakkan diriNya kepada malaikat-malaikat, diberitakan di antara bangsa-bangsa yang tidak mengenal Allah; yang dipercayai di dalam dunia, diangkat dalam kemuliaan." Berdasarkan konteks historis, surat 1 Timotius ditulis oleh Rasul Paulus kepada Timotius untuk menyelesaikan beberapa masalah penggembalaan seperti ajaran sesat, peraturan ibadah, peraturan penetapan pelayan, pelayanan kepada para janda, dan peraturan terhadap jemaat. Paulus mengingatkan Timotius perihal tugas awal yang telah diberikannya kepada Timotius, yaitu menghadapi berbagai bentuk ajaran sesat seperti ajaran Gnostik yang mengajarkan dongeng dan takhayul-takhayul (1:4), serta ajaran Yudaisme yang menekankan hukum Taurat (1:7-8).

Selain masalah tentang bahaya ajaran sesat, di Gereja Efesus juga banyak terdapat orang-orang yang menginginkan posisi sebagai pengajar dalam jemaat. Mereka tidak memahami tujuan utama dari menasehati orang berdosa yaitu kasih yang murni dan bukan hukuman atau bahkan penonjolan diri sang pengajar. Paulus mengingatkan Timotius, bahwa kasih karunia Allah amat besar bagi semua orang berdosa (12-17). Oleh karena itu Paulus mendesak Timotius untuk tetap memperjuangkan pelayanan Injil kasih karunia Allah bagi keselamatan banyak orang berdosa (18-20). Untuk memperjuangkan pelayanan kasih karunia Allah itu Paulus memerintahkan Timotius untuk menaikkan doa syafaat dalam ibadah bersama demi keselamatan banyak orang (2:1-8). Perkembangan gereja yang begitu pesat di Efesus tampaknya menjadi penyebab munculnya banyak pengajar dalam gereja. Budaya kuil Artemis yang mempekerjakan wanita sebagai imam kuil dengan penampilan mewah ternyata mempengaruhi gereja, beberapa wanita dalam gereja mulai menjadi pengajar dengan penampilan yang serupa dengan perempuan (imam) kuil (2:9-15). Paulus juga memberikan kualifikasi yang jelas bagi mereka yang ingin memberikan diri terlibat dalam pelayanan gereja, diantaranya kualifikasi seorang pengawas jemaat (3:1-7) dan kualifikasi diaken (3:8-13). Penetapan kualifikasi para pelayan ini dengan tujuan agar jemaat Allah menjadi saksi kebenaran bagi dunia sekitarnya (3:15-16).

Dalam surat ini Paulus menjelaskan perihal kualifikasi para pelayan dalam gereja, baik itu kualifikasi pengawas atau penilik jemaat dan juga diaken. Paulus menjelaskan tujuan penetapan kualifikasi tersebut, dengan mengatakan "agar jemaat Allah menjadi saksi kebenaran bagi dunia sekitarnya." Inilah keyakinan Paulus bahwa kebenaran tentang Yesus sebagai Juruselamat harus disaksikan. Paulus mengatakan bahwa "agunglah rahasia ibadah

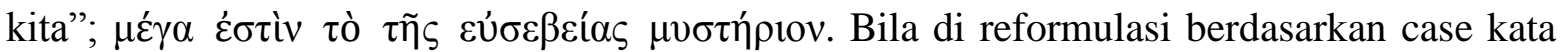
bendanya maka kalimat itu dapat disusun sebagai berikut; $\tau$ ò $\mu v \sigma \tau \eta ́ \rho เ o v \tau \tilde{\eta} \varsigma$

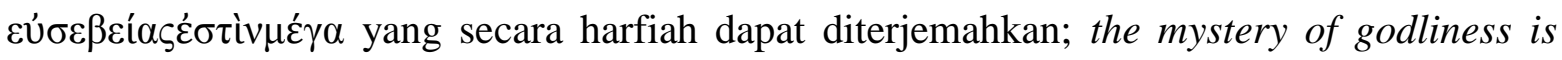

${ }^{4}$ E. Chrisna Wijaya, "Praktik Kenabian Dalam Konteks Sejarah Sosial Budaya Israel Dan Timur Tengah,” Harvester IV, no. 1 (2019), 52. 
great. Kata 'rahasia' $\mu \nu \sigma \tau$ ṕpv artinya 'revelation', dalam bentuk nominative atau berperan sebagai subjek kalimat. Jika melihat pada konteks ayat sebelumnya yaitu mengenai pelayanpelayan gereja dan jemaat yang harus menjadi saksi kebenaran, maka makna kata ini berkaitan dengan dasar iman percaya.

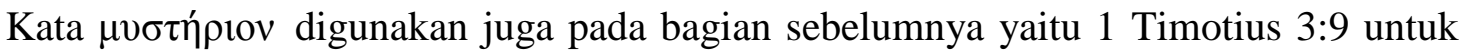
menjelaskan sesuatu yang tersembunyi dari pengetahuan manusia sampai Allah sendiri yang menyatakannya, secara historis yang dimaksud Paulus adalah karya penebusan Allah. ${ }^{5}$ Dalam suratnya kepada jemaat Kolose Paulus menjelaskan tentang rahasia Allah yang besar yaitu kehadiran Kristus di tengah Jemaat; "Allah mau memberitahukan, betapa kaya dan mulianya rahasia itu di antara bangsa-bangsa lain, yaitu: Kristus ada di tengah-tengah kamu, Kristus yang adalah pengharapan akan kemuliaan!” (Kol 1:27). Dalam suratnya kepada jemaat di Korintus, Paulus juga berbicara tentang rahasia Allah yang tersembunyi bagi generasi sebelumnya (1Kor. 2:7), rahasia yang dimaksud Paulus bahwa Yesus Kristus

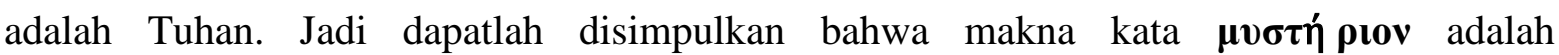
penyingkapan atau penyataan bahwa Yesus adalah Tuhan. Paulus ingin mengatakan bahwa "tidak ada yang dapat membantah bahwa agunglah penyingkapan atau penyataan bahwa Yesus adalah Tuhan.

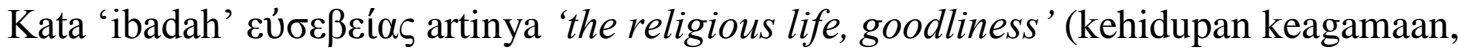
kesalehan), dalam bentuk case genetif yaitu berperan sebagai keterangan kepemilikan. Jadi berdasarkan makna tata bahasanya; penyingkapan bahwa Yesus adalah Tuhan adalah milik dari kehidupan keagamaan atau sebuah kehidupan yang saleh. Kata ini juga digunakan dalam 1Tim. 2:2 yang diterjemahkan 'kesalehan' oleh LAI. Jadi yang dimaksud Paulus dengan frasa "agunglah rahasia ibadah" adalah agungnya penyingkapan bahwa Yesus adalah Tuhan bagi suatu kehidupan keagamaan atau suatu kehidupan yang saleh.

\section{Roh Kudus Memimpin Hamba Tuhan pada Masa Kesukaran}

Dalam teks 1 Timotius 3:16 dijelaskan mengenai keagungan dari penyingkapan bahwa Yesus adalah Tuhan. Dikatakan agungnya penyingkapan itu karena, Allah "telah menyatakan" dirinya dalam rupa manusia. Kata 'menyatakan' pavepó $\omega$ artinya 'he was revealed' dalam bentuk aorist passive indicative (kegiatan kata kerja passive yang sungguhsungguh terjadi, yang terjadi sekali dan selesai pada masa lampau). Secara historical ini menjelaskan manifetasi Allah di dunia melalui pribadi Yesus yang datang untuk menderita bagi dunia. Penyingkapan yang ilahi itu diantaranya adalah melalui peristiwa inkarnasi Yesus, dan kerelaannya disalibkan sebagai korban substitusi.

Selanjutnya dikatakan agungnya penyingkapan itu adalah bahwa Yesus "dibenarkan dalam Roh”. Kata 'dibenarkan' passive indicative (kegiatan kata kerja passive yang sungguh-sungguh terjadi, yang terjadi sekali dan selesai pada masa lampau). Henry Alford mengatakan; ${ }^{6}$

\footnotetext{
${ }^{5}$ Henry Alford, The New Testament For English Reader Vol. 2 (Cambridge: RIVINGTONES, 1865), 530.

${ }^{6}$ Ibid, 530.
} 
I take these events then in their order, refer this to our Lord's Baptism and temptation, in which His Righteousness was approved and proved in The Spirit. He was dwelt on by the Spirit in His Baptism - led up by The Spirit to His great trial, and in The Spirit, He said; the spirit indeed is willing but the flesh is weak".

Oleh karena kata 'dibenarkan' dalam bentuk lampau, maka Henry meyakini bahwa makna dibenarkan ini merujuk kepada peristiwa berdiamnya Roh Kudus dalam pribadi Yesus pada waktu peristiwa Baptisan, dan Roh Kudus yang memimpin Yesus untuk menghadapi pencobaan. Bukti lain yang menunjukan bahwa Yesus adalah benar dan tak berdosa adalah kebangkitanNya dari kematian. Paulus dalam suratnya kepada jemaat Roma mengatakan bahwa; "menurut Roh kekudusan dinyatakan oleh kebangkitan-Nya dari antara orang mati, bahwa Ia adalah Anak Allah yang berkuasa, Yesus Kristus Tuhan kita" (Rom 1:4).

Makna dari kata 'dibenarkan' dalam bagian ini tidak sama penerapannya seperti pada makna pembenaran yang terjadi pada orang Kristen setelah menerima Yesus sebagai juruselamat. Kata ‘dibenarkan' menjelaskan suatu makna bahwa Roh Kudus menolong pelayanan Yesus dan menunjukkan bahwa Yesus adalah benar Anak Allah. Roh Kudus memberikan bukti bahwa Yesus adalah benar Anak Allah melalui turunnya Roh Kudus ke atas pribadi Yesus pada peristiwa pembaptisan (Mat. 3:16), Roh Kudus menginsafkan dunia karena manusia tetap tidak percaya kepada Yesus (Yoh. 16:8-9). Semua hikmat dan pelayanan mukjijat yang dilakukan Yesus di dunia adalah dengan kuasa Roh kudus, sebagai bukti bahwa Yesus adalah Anak Allah.

Ada perdebatan dikalangan para penafsir mengenai siapakah sebenarnya yang dimaksud dengan kata 'Roh' dalam teks ini. Ada yang meyakini bahwa $\pi v \varepsilon \tilde{u} \mu \alpha$ merujuk kepada pribadi Roh Kudus, karena tidak mungkin pribadi Yesus dibenarkan oleh roh atau jiwaNya sendiri, selain itu peranan pribadi Roh Kudus sangat penting dalam seluruh pelayanan Yesus. Jadi dapatlah disimpulkan bahwa makna 'dibenarkan dalam Roh' adalah bahwa Roh Kudus telah menunjukkan pembelaannya atau pertolongannya dalam pelayanan Yesus, untuk menyatakan bahwa Yesus adalah benar Tuhan. Roh Kudus menolong dengan cara berdiam dalam pribadi Yesus, Roh Kudus memimpin Yesus dalam menghadapi pencobaan, Roh Kudus menyertai pelayanan Yesus dengan mukjijat ilahi dan banyak tanda heran, menunjukkan bahwa Yesus adalah yang benar dari Allah, dan menunjukkan bawaha Yesus tak berdosa melalui kebangkitanNya.

\section{Roh Kudus Memperlengkapi dengan Karunia Pelayanan (2Tim. 1:6)}

Karena itulah kuperingatkan engkau untuk mengobarkan karunia Allah yang ada padamu oleh penumpangan tanganku atasmu. (2Ti 1:6). Paulus menyadari bahwa Timotius anak yang dikasihinya masih muda dan kurang memiliki keberanian, dan belum berpengalaman dalam menghadapi banyak masalah pelayanan. Namun Paulus juga memiliki dasar yang kuat dalam mempercayakan pelayanan penggembalaan (jemaat Efesus) kepada Timotius, yaitu iman Timotius yang tulus dan ikhlas. Paulus menyadari bahwa hanya melalui iman sajalah Timotius sanggup bertahan dan menang dari segala tantangan yang harus dihadapinya sebagai seorang prajurit Kristus. Iman yang memungkinkan Timotius memperoleh kasih karunia Allah, dan memungkinkan karya Roh Kudus bekerja dalam kehidupan 
Timotius. Timotius sebagai gembala diperhadapkan dengan tugas yang tidak mudah. Natanael dalam tulisannya menjelaskan bahwa tugas gembala merupakan pekerjaan yang penuh resiko, karena bertugas melindungi domba-doma dari serangan binatang buas, seorang gembala dituntut menjadi pribadi yang pemberani dan tidak mudah menyerah dalam menghadapai situasi sulit. ${ }^{7}$

Dalam surat yang ke dua ini Paulus kembali mengingatkan Timotius untuk tetap bersaksi tentang Yesus sebagai juruselamat, sekalipun Paulus kembali dipenjarakan oleh karena pemberitaan Injil Kristus (1:6-12). Paulus yang berada dalam penjaran Roma tampaknya terus mengikuti perkembangan pelayanan Timotius di Efesus, hal ini terlihat dari nasihat Paulus agar Timotius tetap berpegang pada ajaran sehat (1:13-15). Bahaya penyesataan sangat berpengaruh besar dalam jemaat, bahkan beberapa sahabat Paulus juga berpaling dari ajaran yang sehat, hal inilah yang medorong Paulus untuk memberi warning kepada Timotius untuk tetap berpegang pada Injil sebagai ajaran yang sehat, dan hal itu hanya mungkin dilakukan melalui pertolongan Roh Kudus.

Banyak hal yang memungkinkan seseorang dapat menyimpang dari pemberitaan Injil Kristus Yesus (contohnya Himneus dan Filetus), diantaranya pengaruh ajaran sesat yang menjamur di Efesus dan juga penderitaan yang dialami Paulus dan Timotius karena memberitakan Injil Kristus. Agar Timotius tidak undur dan menyimpang dari panggilannya sebagai pemberita Injil Kristus, maka Paulus menasehatkan Timotius agar menjadi prajurit Kristus yang baik (2:1-13). Paulus menyadari bahwa waktu kematiannya sudah hampir tiba, dia mengatakan bahwa dia telah berhasil mengakhiri pertandingan dengan tetap memelihara iman kepada Tuhan Yesus (2Tim. 4-8). Melalui pesan ini Paulus ingin meneguhkan kesetiaan Timotius untuk tidak berpaling dari tugas yang telah dipercayakan Allah kepadanya, sekalipun Timotius menghadapi tantangan yang sangat berat dalam pelayanannya.

Paulus mengingatkan Timotius, bahwa sebagai prajurit Kristus yang baik Timotius harus berani memberitakan kebenaran (2:14-18). Paulus perihatin dengan pengajaran sesat dan keadaan manusia yang semakin jahat di akhir zaman. Paulus mengkuatirkan jemaat Efesus kembali terpengaruh oleh kerusakan moral yang sedang terjadi di masa akhir (2Tim. 2:14-18; 3:1-9). Itu sebabnya dengan tegas Paulus menasehatkan Timotius untuk tidak malu dan berterus terang dalam memberitakan kebenaran, namun Paulus juga menasehatkan agar dalam memberitakan kebenaran Timotius menghidari perdebatan kosong (2:16).

Paulus menasehatkan Timotius agar menjadi hamba Tuhan dengan kualitas mulia, baik secara moral dan kesabaran dalam melayani orang yang suka melawan terhadap kebenaran yang diberitakan oleh Timotius (2:19-26). Karena itu Paulus menasehatkan Timotius untuk mengobarkan karunia Allah yang ada padanya. Kata 'mengobarkan'

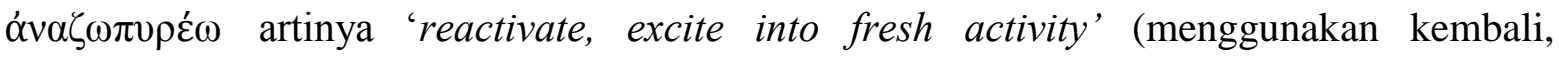
membangkitkan).

${ }^{7}$ Natanael S. Prajogo, "Implementasi Kepemimpinan Gembala Yang Melayani Berdasarkan 1 Petrus 5:2-10 Di Kalangan Gembala Jemaat Gereja Bethel Indonesia Se-Jawa Tengah,” Harvester IV, no. 1 (2019), 4. 


\section{Roh Kudus Menyatakan Nubuat (1Tim. 4:1)}

Tetapi Roh dengan tegas mengatakan bahwa di waktu-waktu kemudian,ada orang yang akan murtad lalu mengikuti roh-roh penyesat danajaran setan-setan (1Tim. 4:1). Untuk menjadikan jemaat sebagai saksi kebenaran, Paulus mendorong dan menuntut Timotius untuk bertekun mengajarkan ajaran-ajaran yang sehat kepada jemaat dan mengupayakan diri menjadi teladan sebagai cermin Injil Kasih karunia yang Paulus ajarkan (4:6-16). Sebab Roh Kudus telah memberitahukan bahwa akan muncul pengajar-pengajar palsu yang ajarannya tampak se-perti ibadah mulia, namun buah kehidupan mereka adalah kekacauan (4:1-5). Itu sebabnya Paulus menuntut Timotius untuk menjadi teladan kebenaran, supaya nyata kuasa dari kebenaran Injil yang Timotius beritakan melalui buah kehidupan rohaninya (4:15-16).

Paulus berulang-ulang menasehati Timotius supaya menjadi teladan dalam perkataan dan tingkah laku. Paulus ingin Timotius menjadi saksi kebenaran melalui perkataan dan sikapnya dalam menegor jemaat yang melakukan pelanggaran baik muda maupun tua (5:12). Untuk menjadi saksi kebenaran, Gereja yang dipimpin oleh Timotius haruslah memperhatikan pelayanan kepada para janda (5:3-16), memperhatikan pelayanan kepada para penatua (5:17-25). Paulus juga menasehati Timotius untuk mengajar jemaat Efesus agar menjadi saksi kebenaran; seorang budak haruslah bersikap hormat kepada tuannya sekalipun tuannya adalah sesama anggota jemaat (6:1-2a).

Paulus menunjukkan kepada Timotius sikap antithesis antara para pengajar sesat dengan pengajar Injil Kasih Karunia Allah. Pengajar sesat adalah penyebab kekacauan dalam jemaat (6:3-5), dan serakah akan uang (6:6-10). Tetapi orang yang mengikuti ajaran Injil Kasih Karunia Allah haruslah menjadi saksi kebenaran dengan cara mengejar keadilan, ibadah, kesetiaan, kesabaran, dan kelemahlembutan (6:11-16). Tidak lupa Paulus mengingatkan orang-orang kaya dalam jemaat untuk menjadi saksi kebenaran melalui perbuatan bajik (6:17-19).

Pada 1 Timotius 3:16, Paulus menunjukkan betapa agungnya penyingkapan Allah bagi kehidupan keagamaan dimana orang percaya harus menjadi saksi kebenaran bahwa Yesus adalah Tuhan. Pada ayat selanjutnya Paulus menegaskan; "tetapi Roh dengan tegas mengatakan bahwa di waktu-waktu kemudian akan ada orang yang murtad". Kata hubung 'tetapi' dari kata $\delta$ غ̀ yang merupakan kata hubung pertentangan yang menunjukkan maksud antitesis antara penjelasan sebelumnya bahwa orang percaya merupakan saksi kebenaran (1Tim. 3:15), dengan kata murtad pada 1 Timotius 4:1.

Albert Barnes mengatakan bahwa ayat ini merupakan bukti bahwa Roh Kudus dapat menyatakan nubuat untuk peristiwa-peristiwa yang akan dihadapi oleh gereja Tuhan. Surat Korintus menjelaskan macam-macam karunia untuk membangun jemaat, salah satu diantaranya adalah karunia untuk bernubuat (1Kor. 12:10). Salah satu contoh pelayan karunia nubuat pada gereja awal adalah Agabus (1Kor. 21:10-11). Rasul Paulus sendiri juga berulang-ulang menunjukkan bahwa dirinya dapat menerima apa yang dikatakan oleh Roh Kudus (Kis. 20:23; 2Tes. 2:3; 2Tim. 3:1), namun demikian tidak ada penjelasan juga yang menyebutkan bahwa Rasul Paulus memiliki karunia bernubuat. Jadi memang tidak begitu jelas apakah bagian ini merupkan nubuat yang disampaikan Roh Kudus kepada Rasul Paulus sendiri atau melalui orang lain, namun bagian ini ingin menegaskan bahwa subjek yang 
menyampaikan nubuat itu adalah Roh Kudus. Roh Kudus memberikan karunia kepada orang-orang tertentu dalam gereja untuk menyampaikan nubuat mengenai peristiwa yang akan segera terjadi pada gereja Tuhan.

Paulus menegaskan bahwa Roh dengan tegas mengatakan, kata 'dengan tegas' $\grave{\eta} \tau \tilde{\omega} \varsigma$ artinya explicitly, in these exact words (secara eksplisit, dalam kata-kata yang tepat). Jadi Roh Kudus menggunakan kata-kata yang jelas untuk menyampaikan nubuatNya. Barnes mengatakan bahwa penggunaan kata $\grave{\eta} \tau \tilde{\omega} \varsigma$ oleh Paulus bertujuan menarik perhatian penuh dari Timotius agar memberikan perhatian terhadap apa yang disampaikan oleh Roh Kudus. Kata 'mengatakan' $\lambda \dot{\varepsilon} \gamma \omega$ artinya 'speak, tell' dalam bentuk present active indicative (suatu kegiatan yang sedang berlangsung secara berulang-ulang dan belum selesai). Paulus memberitahukan kepada Timotius bahwa Roh Kudus sedang (saat-saat itu) menyam-paikan secara berulang, dengan kata-kata yang jelas tentang adanya kemurtadan dan penyesatan.

\section{Roh Kudus Memberikan Kuasa Melayani (1Tim. 4:14)}

Jangan lalai dalam mempergunakan karunia yang ada padamu, yang telah diberikan kepadamu oleh nubuat dan dengan penumpangan tangansidang penatua. (1Ti 4:14). Paulus menabahkan hati Timotius dengan mengingatkannya untuk mempergunakan karunia yang ada padanya. Paulus memerintahkan Timotius untuk tidak lalai dalam mempergunakan karunia. Kata "lalai" ' $\alpha \varepsilon \varepsilon \lambda \varepsilon \dot{\varepsilon} \omega$ artinya 'neglect, disregard' (melalaikan, mengabaikan), dalam bentuk present aktif imperatif yang artinya suatu perintah yang harus dilakukan terus menerus secara sungguh-sungguh. Paulus dengan keras menegaskan kepada Timotius untuk tidak mengabaikan kuasa Roh Kudus yang telah dianugerahkan Allah kepadanya melalui penumpangan tangan para tua-tua.

R. Budiman mengatakan bahwa karunia yang telah Timotius terima untuk melayani jemaat di Efesus, tidak merujuk kepada kepada salah satu karunia seperti yang terdapat dalam 1 Kor. 12:7-10 ataupun dalam Rom. 12:6-8. Karunia yang dimaksud adalah karunia dalam arti yang lebih luas yaitu Kuasa Roh Kudus yang diperlukan untuk melakukan tugas pelayanan penggembalaan. Mengingat kembali akan karunia yang Timotius telah terima sebelumnya, imannya dikuatkan kembali. Paulus berharap Timotius menjadi kuat dan mampu melakukan tugasnya yang berat, karena ia telah menerima kekuatan dari Roh Kudus. Karunia yang diberikan Allah bagi Timotius adalah karunia yang harus dipertanggungjawabkan oleh Timotius, sebab pemberian karunia adalah untuk mengefektifkan pelayanan.

\section{Roh Kudus Membimbing Orang Percaya}

Kehadiran Allah ditengah-tengah umat-Nya dinyatakan dalam pekerjaan Roh Kudus yang memberikan bimbingan kepada orang percaya. Kamus Besar Bahasa Indonesia mendefinisikan kata membimbing sebagai "memegang tangan untuk menuntun." Henry C. Thiessen mendefinisikannya sebagai peranan Roh Kudus dalam memimpin orang percaya agar tidak menuruti keinginan daging. ${ }^{8}$ Dalam Galatia 5:16, 25 orang percaya diperintahkan untuk hidup dan dipimpin oleh Roh Kudus. Seseorang dapat memiliki kearifan dengan cara

${ }^{8}$ Henry C. Thiessen, Teologi Sistematika (Malang: Gandum Mas, 1977), 388. 
mengharapkan dan meminta pertolongan Roh Kudus. ${ }^{9}$ Sebab Roh Kudus mampu memimpin dan mengajar untuk memberikan pemahaman terhadap seluruh kebenaran, Roh Kudus juga mampu membimbing seseorang bagaimana seharusnya menyampaikan argumentasi mengenai kebenaran (Luk. 12:12; Yoh. 16:13,14; Mrk. 13:11).

Verne H. Flecther menjelaskan bahwa orang Kristen dapat mengetahui kehendak Allah melalui Roh Kudus. Hal ini tidak berarti bahwa orang percaya tidak diwajibkan untuk mencarinya sendiri melalui Firman Allah. Namun tidak dapat disangkal bahwa dalam kehidupan orang Kristen terdapat unsur pengilhaman langsung yang menerangkan apa yang harus dilakukan oleh orang percaya. ${ }^{10}$ Filipi 1:9 menjelaskan bahwa Allah dengan rela menyatakan rahasia dari kehendak-Nya. Peranan Roh Kudus dalam membimbing orang percaya tampak dalam penyelesaian polemik yang terjadi dalam gereja mula-mula.

Roh Kudus memberikan bimbingan yang penting mengenai hubungan orang Yahudi dan orang bukan Yahudi. Masalah Yahudi dan non Yahudi tidak hanya terletak pada perbedaan agama kepercayaan, melainkan juga pada masalah ras. Orang-orang Yahudi dengan budaya keeksklusifannya memandang orang di luar rasnya dengan prasangka negatif. Namun seorang Petrus yang didiami oleh Roh Kudus sudi masuk ke rumah Kornelius yang bukan Yahudi, hal ini merupakan langkah maju yang sangat signifikan mengenai hubungan antar sesama manusia pada masa itu (Kis. 10). Langkah maju melalui perubahan pemikiran Petrus, merupakan bimbingan yang dikerjakan oleh Roh Kudus, dan tanpa bimbingan Roh Kudus tidak akan pernah mungkin tercapai tata nilai baru seperti yang terjadi dalam kasus Yahudi dan non Yahudi ini.

Bimbingan Roh Kudus juga tampak dalam sidang di Yerusalem, dimana Yakobus menyatakan bahwa keputusan yang disepakati merupakan keputusan Roh Kudus juga (Kis. 15:28). Nazarius Rumpak menjelaskan bahwa Roh Kudus lah yang memampukan orang percaya dalam menjawab kasus-kasus yang tidak terbicarakan dalam Alkitab, memampukan gereja untuk menggumuli jalan keluar dari persoalan pelik yang mungkin tak terpecahkan, sekalipun telah mengusahakannya dengan berpedoman pada kesaksian-kesaksian Alkitab. ${ }^{11}$

Tulisan rasul Paulus menunjukkan keyakinan bahwa peranan Roh Kudus membimbing orang percaya jauh lebih unggul dari peranan hukum tertulis (2Kor. 3:6). Donal Guthrie mengatakan bahwa Paulus sangat menyakini, bahwa Roh Kuduslah yang memberikan bimbingan mengenai patokan-patokan moral, hingga orang percaya menghasilkan buah dalam kehidupan Kristen (Gal. 5:22). Namun demikian Paulus juga tidak menyangkal tentang tanggung jawab aktif manusia dalam mengerjakan perubahan moral. ${ }^{12}$

\section{Roh Kudus Mengajar}

Segala tulisan yang diilhamkan Allah memang bermanfaat untukmengajar, untuk menyatakan kesalahan, untuk memperbaiki kelakuandan untuk mendidik orang dalam kebenaran. Dengan demikiantiap-tiap manusia kepunyaan Allah diperlengkapi untuk setiap perbuatan baik. (2Ti 3:16-17 ITB). Paulus menyampaikan suatu nubuatan kepada Timotius mengenai

\footnotetext{
${ }^{9}$ Millard J. Erickson, Teologi Kristen (Malang: Gandum Mas, 2004), 190.

${ }^{10}$ Verne H. Flechter, Lihatlah Sang Manusia (Jakarta: BPK Gunung Mulia, 2007), 442.

${ }^{11}$ Nazarius Rumpak, Masa Roh Kudus Dan Kasih Karunia (Jakarta: BPK Gunung Mulia, 1990), 2.

${ }^{12}$ Donal Guthrie, Teologi Perjanjian Baru (Jakarta: BPK Gunung Mulia, 2009), 275.
} 
tantangan pelayanan yang akan dihadapi Timotius di Efesus, dimana perbuatan jahat akan semakin nyata dari kehidupan orang-orang yang menentang Injil Kristus dan ajaran sehat yang telah Paulus ajarkan. Oleh sebab itu Paulus kembali mengingatkan Timotius untuk rela menderita demi Injil Kristus (3:10-13), dan tetap berpegang pada Injil dan Kitab Suci yang memperlengkapi Timotius untuk melakukan perbuatan baik (3:14-17). Dengan kalimat yang tegas dan sungguh, Paulus kembali mengingatkan Timotius agar berani dalam memperkatakan Kebenaran dalam segala waktu dan dengan segala kesabaran (4:1-5). Dengan melakukan semua yang telah dinasehatkan Paulus di atas, maka Timotius akan menjadi prajurit Kristus yang baik. Paulus memberikan contoh nyata dari kehidupannnya sebagai prajurit Kristus yang baik, yg mengakhiri pertandingan dengan baik (4:6-8).

Paulus menasihatkan Timotius bahwa dalam menghadapi tantangan pelayanan, Timotius harus menyadari bahwa Roh Kudus bekerja memperlengkapi manusia untuk dapat melakukan segala perbuatan baik. Roh Kudus menerangi pikiran manusia akan Firman Allah, sehingga manusia mampu melakukan apa yang mulia menurut kehendak Allah. Peranan Roh Kudus dapat dilihat dari penggunaan kata "diilhamkan" dari kata $\theta \epsilon o ́ \pi \nu \in \cup \sigma \tau o \varsigma$ artinya diinspirasikan atau dihembusi Allah. Friberg Lexicon memberikan arti produced by the enabling of his Spirit (dihasilkan dengan kemampuan Roh Kudus). ${ }^{13}$ Jadi peranan Roh Kudus adalah menginspirasikan Firman Allah, sebab itu Roh Kudus memiliki peran penting dalam penulisan Alkitab. Yesus pada waktu akan naik ke Surga telah memberitahukan kepada muridNya bahwa Roh Kudus akan berperan mengingatkan dan mengajar para murid tentang perkataan Yesus (Yoh. 14:26).

Sebelum Yesus naik ke sorga, ia berjanji akan mengutus Roh Kudus kepada para murid dan orang percaya, sebagai penolong yang memipin mereka ke dalam seluruh kebenaran Allah. Roh Kudus sebagai penolong atau parakletos diutus untuk mendampingi, menerangi budi orang percaya, sehingga dapat mengerti apa yang telah diajarkan oleh Yesus (Yoh. 14:26). Salah satu peranan Roh Kudus dalam memimpin orang percaya ke dalam seluruh kebenaran ilahi adalah mengajar orang percaya (Yoh. 14:26; 16:13).

Erickson dalam tulisannya mendefinisikan bahwa peranan Roh Kudus dalam mengajar orang percaya adalah membantu orang-orang percaya masa kini untuk memahami dengan benar berita yang tertulis dalam Kitab Suci. ${ }^{14}$ Setiap orang percaya yang telah mengalami peristiwa lahir baru di dalam hidupnya ada Roh Kudus, dan Roh Kudus yang telah mengilhami penulisan Alkitab akan menerangi pikiran orang-orang percaya tersebut untuk mengerti segala hal tentang Allah; yaitu segala hal yang baik dan berkenan menurut kehendak Allah melalui isi Alkitab.

E.P Ginting dalam bukunya mengatakan; “jika para Nabi atau Rasul sebagai penulispenulis Kitab berbicara atas nama Allah dengan kekuatan Roh Kudus (2Pet. 1:2), maka Roh Kuduslah yang memberikan pengertian tentang apa yang mereka tulis. ${ }^{15}$ Hal ini dapat

\footnotetext{
${ }^{13}$ Barbara Friberg, Timothy Friberg, Neva F. Miller, "Analytical Lexicon of The Greek New Testament" (Grand Rapid: Baker Books, 2000).

${ }^{14}$ Millard J. Erickson, Teologi Kristen, 53.

${ }^{15}$ E.P. Ginting, Khotbah Dan Pengkhotbah (Jakarta: BPK Gunung Mulia, 2002), 40.
} 
dimungkinkan sebab Roh Kudus mampu mendeskripsikan secara lengkap dan benar apa yang menjadi kehendak Allah (1Kor. 2:10-11). Peranan Roh Kudus mengajar orang percaya dinyatakan melalui pemberian hikmat kepada orang percaya, untuk dapat memahami sesuatu yang tidak mungkin dipahami melalui akal pikiran biasa (1 Kor. 2:13). Mengenai ayat ini Millad J. Erickson menjelaskan:

Karunia-karunia Roh Kudus diberikan dalam kata-kata yang diajarkan ( $\delta\llcorner\delta \alpha \kappa \tau o ́ \varsigma)$ oleh Roh dan bukan oleh hikmat manusia (1Kor. 2:13). Dari semua pertimbangan ini, tampaklah bahwa Paulus tidak sedang mengatakan bahwa orang-orang yang tidak rohani itu mengerti tetapi tidak menerima. Tetapi sebaliknya, orang-orang yang tidak rohani itu tidak menerima, setidak-tidaknya sebagian karena mereka tidak memahami. ${ }^{16}$

Peranan Roh Kudus menjadi hal vital dalam memahami segala sesuatu yang Allah ingin nyatakan kepada orang percaya. Sebab hikmat Allah itu di luar jangkauan mata, telinga, dan pikiran manusia. Ia tidak tunduk kepada penelitian ilmiah, juga terhadap imajinasi. Hikmat Allah sama sekali di luar batas dan daya ukur akal kita yang sempit dan terbatas, kecuali Allah sendiri menyatakannya.

Namun apa yang tidak pernah dilihat oleh mata, yang tidak pernah timbul di dalam hati manusia: semua itu disediakan Allah bagi yang mengasihi Dia (1Korintus 2:9), yaitu tuntunan-Nya melalui Roh Kudus untuk mengajari orang percaya. Betapa pentingnya pencerahan yang diberikan oleh Roh Kudus untuk mengerti Firman Allah, sampai-sampai penulis Surat Yohanes menggunakan kalimat “...tidak perlu kamu diajar oleh orang lain” (1Yoh. 2:27). Roh Kudus mengajar dengan cara memperbaharui akal budi orang percaya, untuk memahami kebenaran Firman Allah. Roh Kudus adalah Guru yang akan mengarahkan akal budi orang percaya, sebab itu akal atau nalar orang percaya tidak diabaikan. Namun E.P Ginting menegaskan bahwa akal budi digunakan bukan untuk mengkritik Firman, melainkan dipergunakan untuk menggumuli, berusaha memahami, mengahayati, dan merelevansikan Firman dalam kehidupan sehari-hari. ${ }^{17}$ Selain melalui pembaharuan akal budi, Roh Kudus juga mengajar orang percaya melalui gereja yang merupakan tubuh Kristus. Roh Kudus mengajar orang percaya secara tak langsung dengan perantaraan saudara seiman dan jemaat setempat (Ef. 3:18-19).

Peran Roh Kudus mengajar orang percaya tidak hanya dibatasi pada area agama saja, melainkan pada seluruh area hidup manusia. G. C Van Niftrik dalam bukunya menjelaskan peranan Roh Kudus dalam mengajar orang percaya melalui Alkitab, untuk menjelaskan bahwa Kristus merupakan Tuan yang mengatur dan bertanggungjawab di segala lapangan hidup. ${ }^{18}$ Lapangan hidup orang percaya hanya akan menjadi lebih baik, bila orang percaya tetap berdoa (Maz. 119:19) supaya Roh Kudus dengan perantaraan Alkitab menerangkan apa yang harus dilakukan orang percaya, yang sesuai dengan kehendak Allah. Roh Kudus merupakan Agen yang mengajarkan wahyu Allah pada orang percaya. John R.W Stoot dalam bukunya yang berjudul "Basic Chritian Leadrship" mengatakan: "Paul give us a comprehensive statement of the ministry of the Holy Spirit as the agent of the divine

\footnotetext{
${ }^{16}$ Millard J. Erickson, Teologi Kristen, 323.

${ }^{17}$ E.P. Ginting, Khotbah Dan Pengkhotbah, 41.

${ }^{18}$ G.C Van Niftrik \& B.J Boland, Dogmatika Masa Kini (Jakarta: BPK Gunung Mulia, 2008), 401.
} 
revelation. He presented to us in four stages as "searching", "revealing", "inspiring”, and "enlightening."19

\section{Roh Kudus Menyingkapkan Pikiran Allah}

Tahap pertama yang Roh Kudus kerjakan dalam rangka mengajar orang percaya adalah menyelidiki pikiran dan kehendak Allah (1Kor. 2:10-11). Ini merupakan pekerjaan yang dilakukan pribadi Roh Kudus, sebab Roh Kudus adalah pribadi yang memiliki akal pikiran yang melaluinya dapat menyelidiki pikiran dan kehendak-kehendak Allah. Penggunaan istilah "menyelidiki" sepadan dengan istilah yang sering digunakan untuk menjelaskan pekerjaan orang Yahudi yang berusaha menyelidiki Kitab-kitab Suci. Istilah ini juga menggambarkan ketelitian para petugas beacukai. Paulus mungkin meminjam istilah 'dalam' dari perbendaharaan kata bidat Gnostik, untuk menjelaskan keberadaan Allah yang tak terukur kedalaman-Nya dalam (1Kor. 2:10). Dengan istilah ini Paulus secara terus terang menyatakan bahwa Roh Kudus menyelidiki kedalaman-kedalaman Allah. John Stott mengatakan "at all events, the holy spirit is depicted as restlessly inquisitive researcher, even-deep sea diver seeking to fathom the deepest depths of the being of God." "20

Kemampuan Roh Kudus dalam menyelidiki pikiran Allah, juga digambarkan dalam bentuk pengertian manusia tentang dirinya sendiri. "Siapa gerangan di antara manusia yang tahu, apa yang terdapat di dalam diri manusia selain roh manusia itu sendiri?" (1Kor. 2:11). Ungkapan 'Apa yang terdapat' menunjuk kepada hal-hal khusus yang hanya diketahui simanusia itu sendiri. Manusia sekalipun tidak mungkin dapat menyelami sepenuhnya keberadaan diri seorang manusia lainnya, selain roh simanusia itu sendiri. Kemampuan diri dalam memahami diri sendiri inilah yang digunakan Paulus untuk menggambarkan kapasitas kemampuan Roh Kudus dalam meyelidiki pikiran Allah. Itu sebabnya dalam 1Korintus 2:11b dikatakan bahwa tidak ada orang yang tahu, apa yang terdapat di dalam diri Allah selain Roh Allah (Roh Kudus) itu sendiri.

Langkah selanjutnya setelah Roh Kudus menyelidiki apa yang ada dalam pikiran Allah adalah menyatakan apa yang diselidiki-Nya. Dalam 1Korintus 2:10 dikatakan bahwa "kepada kita (para rasul) Allah telah menyatakannya oleh Roh." Kemudian dalam 1Korintus 2:12 Paulus menguraikannya: "Kita (para rasul) tidak menerima roh dunia, tetapi roh yang berasal dari Allah (yaitu Roh yang menyelidik dan yang mengetahui), supaya ditahu, apa yang dikaruniakan Allah kepada kita." Jadi Roh Kudus memampukan memahami bahwa keselamatan adalah anugerah Allah.

Peranan Roh Kudus menyatakan ajaran Injil kasih karunia, Dia menyatakan apa yang telah Allah buat untuk orang-orang berdosa yang sebenarnya tidak pantas menerima kasih karunia. Paulus menyatakan bahwa Allah telah mengutus Anak-Nya untuk mati di salib bagi dosa-dosa manusia dan bangkit kembali, dan melalui iman dan baptisan pertobatan maka manusia turut mati bersama Dia dan bangkit kembali dengan Dia, mengalami suatu kehidupan baru di dalam Dia. Injil ajaib seperti inilah yang Paulus ungkapkan kepada orang

\footnotetext{
${ }^{19}$ John R.W Stoot, Basic Christian Leadership: Biblical Models Of Church, Gospel And Ministry (Downers Gorve: InterVarsity Press, 2002), 61.

${ }^{20}$ Ibid, 62-63.
} 
percaya dalam surat- suratnya. Pertanyaannya adalah bagaimana Paulus dapat mengetahui semua ini? Bagaimana Paulus dapat membuat uraian selengkap ini tentang konsep keselamatan? Menurut John Stoot Jawabannya adalah "he had received the Holy Spirit to interpret his experience to him. Thus the searching Spirit became the revealing Spirit, making God and his work of salvation known to the biblical authors". ${ }^{21}$

\section{Roh Kudus Mengilhami Pemberitaan Firman Allah}

Setelah Roh Kudus menyatakan apa yang ddikehendaki Allah untuk dinyatakan, tahap selanjutnya dari peranan Roh Kudus mengajar adalah mengilhamkan. Dalam 1 Korintus 2:13b dikatakan bahwa para Rasul berkata-kata tentang karunia-karunia Allah dengan perkataan yang bukan diajarkan oleh hikmat manusia, melainkan oleh Roh. Dalam ayat sebelumnya menjelaskan ajaran apa yang diterima oleh Paulus dari Roh Kudus, dan pada ayat 13 menjelaskan ajaran apa yang disampaikan oleh Paulus. Roh yang menyelidiki pikiran Allah telah menyatakan ajaran tentang Allah dan karya keselamatan ke dalam pikiran para Rasul, selanjutnya mengilhami para Rasul dalam meneruskan penyampaian ajaran Firman Allah itu kepada orang-orang lain. Jadi sama seperti Roh tidak menyimpan hasilhasil penyelidikan-Nya untuk diri-Nya sendiri, demikian pula para rasul tidak menyimpan penyataan dari-Nya itu untuk diri mereka sendiri.

Dalam menjelaskan content ajaran Firman yang telah dinyatakan oleh Roh Kudus dalam pikiran para Rasul, Paulus mengunakan istilah "berkata-kata" dan "perkataan" yang diajarkan oleh Roh. Mengenai istilah ini John Stoot menjelaskan bahwa: Verbal inspiration means that what the Holy Spirit spoke through the biblical authors (understood according to its literary genre, its plain, natural meaning, the intention of the human authors and each context) is true and without error. ${ }^{22}$ (pengilhaman secara lisan artinya bahwa apa yang Roh Kudus bicarakan melalui para penulis Alkitab [pemahaman menurut jenis sastra yang digunakan, kepolosan, alamiahnya, makna dasar, maksud penulis dan tiap konteksnya] adalah benar dan tanpa kesalahan).

Allah Roh Kudus yang telah mengilhami para Rasul dalam menyampaikan ajaran kepada orang percaya, dan juga bagi umat Tuhan pada masa kini melalui Alkitab yang tanpa salah, selanjutnya mengajar orang-orang percaya dengan cara menerangi pikirannya. Roh Kudus yang telah mengilhami perkataan para Rasul untuk menyapaikan ajaran-Nya, selanjutnya dengan giat berkarya di dalam diri mereka yang membaca tulisan para Rasul tersebut. Jadi Roh Kudus bekerja di dalam keduanya, yaitu mengilhamkan firman-Nya kepada para Rasul dan menerangi para pendengar Firman itu. Secara tidak langsung hal ini disinggung dalam 1 Korintus 2:13a, dimana Roh Kudus menafsirkan kebenaran-kebenaran rohani kepada mereka yang memiliki Roh (orang yang telah mengalami kelahiran baru).

\section{KESIMPULAN}

1 dan 2 Timotius telah mengajarkan Timotius untuk memahami peranan Roh Kudus dalam menghadapi banyak masalah penggembalaan yang terjadi di jemaat Efesus, di antaranya adalah bahwa Roh Kudus memberikan peneguhan bahwa Yesus adalah Tuhan, memimpin

\footnotetext{
${ }^{21}$ Ibid, 64.

${ }^{22}$ Ibid, 67.
} 
hamba Tuhan pada masa kesukaran, memperlengkapi hamba Tuhan dengan karunia pelayanan (2 Tim. 1:6), menyatakan nubuat (1Tim. 4:1), memberikan kuasa melayani (1Tim. 4:14), membimbing orang percaya, mengajar, menyingkapkan pikiran Allah, mengilhami pemberitaan firman Allah.

\section{REFERENSI}

Anas Sudijono. Pengantar Evaluasi Pendidikan. Jakarta: PT. Raja Grafindo Persada, 1996.

Anwar Hadi. Pemahaman Dan Penerapan ISO/IEC 17025 Persyaratan Umum Kompetensi Laboraturium Pengujian Dan Laboraturium Kalibrasi. Jakarta: Gramedia, 2007.

Barbara Friberg, Timothy Friberg, Neva F. Miller. "Analytical Lexicon of The Greek New Testament." Grand Rapid: Baker Books, 2000.

Donal Guthrie. Teologi Perjanjian Baru. Jakarta: BPK Gunung Mulia, 2009.

E. Chrisna Wijaya. "Praktik Kenabian Dalam Konteks Sejarah Sosial Budaya Israel Dan Timur Tengah." Harvester IV, no. 1 (2019).

E.P. Ginting. Khotbah Dan Pengkhotbah. Jakarta: BPK Gunung Mulia, 2002.

G.C Van Niftrik \& B.J Boland. Dogmatika Masa Kini. Jakarta: BPK Gunung Mulia, 2008.

Gidion. Metode Penelitian Teologi. Semarang: KAO Press, 2015. https://isbn.perpusnas.go.id/Account/SearchBuku?searchCat=Judul\&searchTxt=MET ODE+PENELITIAN+TEOLOGI.

Guthrie, Donald G. "The Pastoral Epistles and the Mind of Paul." In The Tyndale New Testament Lecture, 1956.

Hendry C. Thiessen. Teologi Sistematika. Malang: Gandum Mas, 1977.

Henry Alford. The New Testament For English Reader Vol. 2. Cambridge: RIVINGTONES, 1865.

John R.W Stoot. Basic Christian Leadership: Biblical Models Of Church, Gospel And Ministr. Downers Gorve: InterVarsity Press, 2002.

Millard J. Erickson. Teologi Kristen. Malang: Gandum Mas, 2004.

Natanael S. Prajogo. "Implementasi Kepemimpinan Gembala Yang Melayani Berdasarkan 1 Petrus 5:2-10 Di Kalangan Gembala Jemaat Gereja Bethel Indonesia Se-Jawa Tengah.” Harvester IV, no. 1 (2019).

Nazarius Rumpak. Masa Roh Kudus Dan Kasih Karunia. Jakarta: BPK Gunung Mulia, 1990.

OFM, Nico Syukur Dister. Pengantar Teologia. Yogyakarta: KANISIUS, 1991.

Verne H. Flechter. Lihatlah Sang Manusia. Jakarta: BPK Gunung Mulia, 2007. 